\title{
ERK knockdown suppress cell biological activities via regulation CD59 in breast cancer
}

\section{Type}

Research paper

\section{Keywords}

breast cancer, CD59, MCF-7, ERK, biological activities, MDA-MB-231

\begin{abstract}
Introduction

It has been unclear that ERK play the effects and relative mechanism in breast cancer development. The purpose of this work was to discuss the ERK play the effect in breast cancer and relative mechanisms.

Material and methods

Evaluating ERK and CD59 proteins expression in difference tissue from patients by IHC assay. Using MCF-7 and MDA-MB-231 cell lines which were breast cancer cell lines as target cell lines in our study. In vitro study, evaluating cell biological activities including proliferation, apoptosis, cell cycle, invasion, adherent and migration by MTT, clone test, TUNEL assay, flow cytometry and wound healing. And measuring relative proteins expressions by WB assay. In vivo study, measuring tumor weight and volume, the apoptosis cell number were evaluated by TUNEL assay and relative proteins expressions by IHC assay.
\end{abstract}

\section{Results}

Compared with adjacent normal tissue, the ERK and CD59 proteins expression were significantly increased in breast cancer tissues ( $P \square 0.001$, respectively). In vitro and vivo studies, with ERK knockdown, the cell biological activities were significantly depressed with CD59 suppressing ( $\mathrm{P} \square 0.001$, respectively). And the relative proteins including CD59, PKD, P53, E-cadherin and Vimentin were significantly differences ( $P \square 0.001$, respectively).

\section{Conclusions}

ERK play an oncology gene in breast cancer development, ERK inhibitor had effects to suppress breast cancer biological via regulation CD59 in vitro and vivo study. 


\section{ERK knockdown suppress cell biological activities via regulation CD59 in breast cancer}

Running Title: ERK and breast cancer

Abstract

Introduction: The purpose of this work was to discuss the ERK play the effect in breast cancer and relative mechanisms.

Methods: Some previous studies found ERK was closely correlation with CD59 in cancer. In our clinical data, Evaluating ERK and CD59 proteins expression in difference tissue from patients by IHC assay. Using MCF-7 and MDA-MB-231 cell lines which were breast cancer cell lines as target cell lines in our study. In vitro study, evaluating cell biological activities including proliferation, apoptosis, cell cycle, invasion, adherent and migration by MTT, clone test, TUNEL assay, flow cytometry and wound healing. And measuring relative proteins expressions by WB assay. In vivo study, measuring tumor weight and volume, the apoptosis cell number were evaluated by TUNEL assay and relative proteins expressions by IHC assay.

Results: Compared with adjacent normal tissue, the ERK and CD59 proteins expression were significantly increased in breast cancer tissues $(\mathrm{P}<0.001$, respectively).In vitro 
and vivo studies, with ERK knockdown, the cell biological activities were significantly depressed with CD59 suppressing $(\mathrm{P}<0.001$, respectively). And the relative proteins including CD59, PKD, P53, E-cadherin and Vimentin were significantly differences (P $<0.001$, respectively).

Conclusion: ERK play an oncology gene in breast cancer development, ERK inhibitor had effects to suppress breast cancer biological via regulation CD59 in vitro and vivo study.

Key words: ERK; CD59; breast cancer; MDA-MB-231; MCF-7; biological activities

Running Title: ERK and breast cancer

Introduction

Breast cancer is the most common malignant tumor in females around the world, and also the main cause of female deaths worldwide [1]. According to the reports, China accounts for $12.2 \%$ of all newly diagnosed cases of breast cancer and $9.6 \%$ of all deaths from breast cancer globally. There is a significant improvement in the clinical cure rate of breast cancer patients resulted from early diagnosis and treatment. However, recurrence and metastasis is still the primary cause of death in breast cancer patients [3]. Increasingly more studies support that tumor cells can activate their own complement system $[4,5]$. Specifically, tumor cells can up-regulate complement control proteins (mCRPs) to avoid the killing effect of complement. Among them, CD59 is the most important one of the three mCRPs [5, 6]. The complement system is an essential effector in the process of tumor immunity. mCRPs, especially CD59, may play an important role in preventing tumor immune evasion. As evidenced by prior study, inhibition of CD59 expression may exert sensitizing effect on tumor cells [7]. 
Proteomic quantitative analysis conducted by some scholars' supports that CD59 may associate with the metastasis of breast cancer [8]. Besides, some scholars have found that CD59 can be recognized as a prognostic factor for breast cancer patients underwent surgical treatment [9]. However, it remains to be elaborated concerning the specific mechanism so far.

Extracellular signal-regulated kinase (ERK) signaling pathway, also known as mitogen activated protein kinase/ERK (MAPK/ERK) signaling pathway or Ras-RafMEK-ERK cascade reaction, is an important signaling pathway that involves in multiple physiological processes of cells, such as cell growth, development, division, death [10]. ERK is an important member of MAPK family, and its signaling pathway is the core of signaling network involved in cell growth, development and division. However, it needs to be reported in detail whether there is a correlation between ERK and CD59 and the related mechanism in the development of breast cancer. Our study was carried out to analyze the possible mechanism of ERK-CD59 signaling pathway by detecting the expression of CD59 in different breast tumor cell lines from cell land protein levels. The present study is expected to discuss the biological significance of ERK-CD59 regulation in vitro and in vivo by using breast tumor cells and establishing nude mice tumor-bearing model.

\section{Materials and Methods}

\section{Clinical Data}

All fresh tissue samples were collected from the Third Hospital of Nanchang from December 2016 to November 2018, including 60 cases of breast cancer tissue and 60 cases of adjacent normal breast cancer tissue. The adjacent normal tissue was $>5 \mathrm{~cm}$ from the margin of the tumor, and all tissues were confirmed by pathology. All enrolled patients in this study signed informed consent. The included 60 cases of breast cancer were female, ranging from 25-72 years old, with the median age of 48 years old. The cancer tissue of all cases were confirmed to be invasive breast cancer by postoperative pathology. No radiotherapy or chemotherapy was received in those cases before operation. All the cases had complete phase I clinical and pathological data. The 
collected specimens were fixed with $10 \%$ neutral formalin, and then dehydrated, embedded in paraffin, stained with HE and observed under light microscope.

\section{Immunohistochemistry (IHC)}

Test of tumor samples with polyclonal antibody was performed by immunohistochemistry (EnVision Two-step). Proteintech Group Brand, the immunohistochemical kit, was purchased from Wuhan Jiayuan Biomedical Engineering Co., Ltd., with the working concentration pre-set at 1:1,000. Phosphate buffer saline (PBS) was used as the negative control. The experiment was carried out in strict accordance with the instructions of Immunohistochemistry Kit. The staining results were randomly reviewed by two pathologists. With a photography under $400 \times$ field of view, the protein expression was analyzed by Image J image analysis software.

\section{Cell Culture}

Breast tumor cell lines MDA-MB-231 and MCF-7 were provided by ATCC, USA. MDA-MB-231 cells were cultured in 90\% L-15+10\%FBS medium, while MCF-7 cells in $90 \%$ RPMI1640+10\%FBS medium. All cells were cultured in an incubator with $5 \% \mathrm{CO}_{2}$ and saturated humidity at $37^{\circ} \mathrm{C}$.

\section{MTT Assay}

After cell digestion and counting, cells were prepared into cell suspension at concentration of $5 \times 10^{4}$ cells $/ \mathrm{mL}$, followed by the addition of $100 \mu \mathrm{L}$ cell suspension into the 96-well cell culture plate. The 96-well cell culture plate was then placed in 5\% $\mathrm{CO}_{2}$ incubator at $37^{\circ} \mathrm{C}$ for $24 \mathrm{~h}$. Plasmid transfection was performed according to the trial protocol, and the negative control group was set up simultaneously[11]. After that, the 96-well cell culture plate was placed in $5 \% \mathrm{CO}_{2}$ incubator at $37^{\circ} \mathrm{C}$ for another $48 \mathrm{~h}$ of incubation. In the next step, the 96-well cell culture plate was stained with MTT solution and the OD value was calculated at wavelength of $\lambda=490 \mathrm{~nm}$ for the calculation of cell proliferation rate in each group. 


\section{Cloning Experiment}

The monolayer culture cells at logarithmic growth phase were dispersed into single cell suspension by general passage method. After cell counting, the cell suspension was diluted with gradient multiple, inoculated into a 6-well cell culture plate containing 2 $\mathrm{mL}$ of culture medium at a cell density of 500 cells per well. Then, the culture plate was shaken gently in the direction of "the sign of the cross" to make the cells disperse evenly. Afterwards, the cell culture plate was placed into the $5 \% \mathrm{CO}_{2}$ incubator at $37^{\circ} \mathrm{C}$ with saturated humidity for $24 \mathrm{~h}$ until cell attachment to the wall. After $12 \mathrm{~d}$ of culture, the culture was cultured after discarding the culture medium, followed by two times of washing with PBS. An amount of $5 \mathrm{ml}$ of anhydrous ethanol was added for $15 \mathrm{~min}$ of fixation. With the fixation fluid discarded, the Giemsa staining solution was added for 10-30min of staining, then washed slowly with running water and dried in the air. Finally, the clones were counted directly with the naked eye.

\section{Cell TUNEL Assay}

Natural air-dried cell samples (cell smears or slides) were selected and immersed in the $4 \%$ paraformaldehyde for 30 min or overnight to improve cell permeability. After PBS immersion $(3 \min \times 3)$, samples were added with $1 \%$ Triton-100 at room temperature for $15 \mathrm{~min}$. After another PBS soaking $(3 \mathrm{~min} \times 3)$, samples were treated with $3 \% \mathrm{H}_{2} \mathrm{O}_{2}$-methanol solution for $15 \mathrm{~min}$, followed by PBS washing $(3 \mathrm{~min} \times 3)$. In the next step, each sample were dropped with and treated by the prepared $100 \mathrm{ul}$ protease $\mathrm{K}$ at $37^{\circ} \mathrm{C}$ for $30 \mathrm{~min}$, followed by adding $100 \mathrm{ul}$ of Streptacidin-TRITC labeled working solution and reaction in dark and humid environment at $37^{\circ} \mathrm{C}$ for $1 \mathrm{~h}$. With another PBS immersion $(3 \min \times 3)$, samples were added with 100 ul DAPI working solution for reaction in dark at $37^{\circ} \mathrm{C}$ for $5 \mathrm{~min}$. After three times of PBS washing (5min each), samples were observed under the fluorescence microscope.

\section{Annexin-V FITC/PI Double Staining to Detect Apoptosis and Cell Cycle}

Cells at the adjusted density of $5 \times 10^{5}$ were collected after PBS washing twice and subsequent centrifugation (1000 $\mathrm{g} \times 5 \mathrm{~min})$. After that, an amount of $500 \mu \mathrm{L}$ of Binding 
Buffer was added for the suspension of cells, followed by mixing with $5 \mu \mathrm{L}$ Annexin V-FITC and then the addition of $5 \mu \mathrm{L}$ Propidium Iodide. After mixing, a reaction was continued in dark at room temperature for $5-15 \mathrm{~min}$. Apoptosis and cell cycle were detected by flow cytometry.

\section{Transwell Assay to Detect Cell Invasion}

With the removal of serum, cells received starvation culture with incomplete culture medium for $24 \mathrm{~h}$. Matrigel was melt overnight at $4^{\circ} \mathrm{C}$, and the melt Matrigel was then diluted twice with incomplete culture medium. An amount of $30 \mu \mathrm{L}$ diluted Matrigel was added to the upper chamber of Transwell and incubate at $37^{\circ} \mathrm{C}$ for 120 min to polymerize Matrigel into glue. After cell digestion and counting, cells were adjusted at the density of $1 \times 10^{5}$ cells $/ \mathrm{mL}$ with incomplete culture medium. Then, 100 $\mu \mathrm{L}$ cell suspension was collected to add into the Transwell chamber, with $500 \mu \mathrm{L}$ culture medium containing $20 \% \mathrm{FBS}$ into the lower chamber. After that, the $24-$ well cell culture plate was placed into the $5 \% \mathrm{CO}_{2}$ incubator for $24 \mathrm{~h}$ of culture at $37^{\circ} \mathrm{C}$. At the end of the culture, the matrix glue and the cells were wiped in the upper chamber with a cotton swab, and the Transwell was removed and inverted to dry naturally. Another amount of $500 \mu \mathrm{L}$ of crystal violet containing $0.1 \%$ crystal violet was added into the 24 -well culture plate, followed by the placement of the chamber to immerse the membrane in the dye for $30 \mathrm{~min}$ at $37^{\circ} \mathrm{C}$. With PBS washing after staining, 3 fields of view were taken in diameter for photography (magnification, 200×) and counting.

\section{Wound healing Assay to Detect Cell Migration}

Cells in the logarithmic growth period were digested and inoculated into the 6well plate. The next day, the 6-well plate was evenly scratched with a sterile pipette tip when the cell confluence reached about $60 \%$. After floating cells washing with PBS, cells were transferred to fresh culture medium and placed into the cell incubator for further $24 \mathrm{~h}$ of culture. At the end of culture, cells were photographed (magnification, $200 \times$ ) to measure the distance of cell migration. 


\section{Cell Adhesion Assay}

The FN was diluted with serum-free medium at the final concentration of $10 \mathrm{mg} / \mathrm{L}$ and added to 96 -well plate with $50 \mu \mathrm{L}$ per well for overnight culture at $4{ }^{\circ} \mathrm{C}$. Following the discarding of excess liquid, cells were digested and counted, followed by cell density adjustment to $1 \times 10^{5}$ cells $/ \mathrm{mL}$ with incomplete culture medium. Cells were then transferred into the $5 \% \mathrm{CO}_{2}$ incubator at $37^{\circ} \mathrm{C}$ for $1 \mathrm{~h}$, with $100 \mu \mathrm{L}$ cells per well. Culture medium was discarded at the end of culture, and the cells not adherent was removed by PBS washing, followed by cell photography and counting under the microscope.

\section{Western Blot Detection}

With the addition of pre-cooled lysate for cell lysis for $15 \mathrm{minm}$, the protein was collected by obtaining the supernatant after centrifugation $(1200 \mathrm{~g} / \mathrm{min})$ at $4^{\circ} \mathrm{C}$ for $5 \mathrm{~min}$. Protein concentration was calculated by BCA colorimetry. After the protein was separated by SDS-PAGE, it was transferred to PVDF membrane and then sealed with $5 \%$ skimmed milk powder for $2 \mathrm{~h}$. The primary antibody was diluted according to the instruction to the required concentration with the blocking solution, followed by incubation overnight at $4{ }^{\circ} \mathrm{C}$. Following washing by TBST three times ( $5 \mathrm{~min}$ each), the HRP labeled secondary antibody was diluted according to the dosage, and incubated at $37^{\circ} \mathrm{C}$ for $1 \mathrm{~h}$. With another TBST washing for three times ( 5 min each), enhanced chemiluminescence (ECL) was used for protein expression detection, and Image $\mathbf{J}$ software was used for gray analysis.

\section{Tumor-bearing Experiment}

A total of 42 4-week-old female BALB/c nude mice (Laboratory of Animal Experimental Center, Nanjing Medical University) were used as experimental animals, with a body mass of $18-24 \mathrm{~g}$ and an average of $(21.14 \pm 2.04) \mathrm{g}$. The human breast cancer MCF-7 cells $(0.2 \mathrm{ml})$ at the logarithmic growth phase with adjusted cell density of $4 \times 10^{5} / \mathrm{ml}$ were inoculated into the right armpit of each nude mouse. NC group was used normal MCF-7 cell; Mock group was used MCF-7 cell which transfected with vector; 
ERK group was used MCF-7 cell which transfected with ERK gene; ERK+siCD59 group was used MCF-7 cell which transfected with ERK gene and siCD59 which inhibited CD59; ERK inhibitor group was used MCF-7 cell which transfected with ERK inhibitor; ERK inhibitor+CD59 group was used MCF-7 cell which transfected with ERK inhibitor and CD59 gene. After that, mice were raised routinely for a continuous raising of $15 \mathrm{~d}$, with the tumor volume observed once a week. The nude mice were killed and sampled $15 \mathrm{~d}$ later.

\section{TUNEL Detection}

According to routine procedure of dewaxing and hydration, the slices were soaked in xylene for $5 \mathrm{~min}$, and then soaked in a new xylene for another $5 \mathrm{~min}$. For gradient ethanol dehydration, slices were immersed in absolute ethanol for $5 \mathrm{~min}, 95 \%$ ethanol for $5 \mathrm{~min}, 85 \%$ ethanol for $5 \mathrm{~min}$, and 70\% ethanol for $5 \mathrm{~min}$, followed by PBS washing ( $3 \mathrm{~min} \times 3$ times). Subsequent reaction was continued at $37^{\circ} \mathrm{C}$ for $15 \mathrm{~min}$ with the addition of a ready-to-use solution prepared according to the ratio of $90 \mu 11 \times \mathrm{PBS}$ and $10 \mu \mathrm{l}$ 10xProteinase $\mathrm{K}$. Then, $100 \mu \mathrm{L}$ DNaseI reaction solution was prepared according to the sample. After that, 1\% Triton-100 was added to the sample for reaction at room temperature for $15 \mathrm{~min}$. With a soaking in PBS three times (5min each), samples were treated with $3 \% \mathrm{H}_{2} \mathrm{O}_{2}$-methanol solution for $15 \mathrm{~min}$. After PBS immersion three times (5min each), 100 $\mu \mathrm{l}$ TdT enzyme reaction solution was added to each sample, and reacted for $1 \mathrm{~h}$ at $37^{\circ} \mathrm{C}$ under wet condition in dark, followed by another PBS immersion three times (5min each). Then, 100ul Streptavadin-HRP was supplemented to samples for $10 \mathrm{~min}$ of reaction at $37^{\circ} \mathrm{C}$ under wet condition in dark. With another immersion in PBS three times (5min each), 2 drops of DAB solution freshly prepared to each sample to observe the staining depth under the microscope, and stop immediately after well staining. With gentle washing by tap water for $15 \mathrm{~min}$ and development termination with distilled water, the slices were placed into hematoxylin solution for $10 \mathrm{~min}$, which was then placed into hydrochloric acid-methanol solution after washing with distilled water, followed y washing with distilled water immediately. In the next step, the slices were soaked in $70 \%$ ethanol for $5 \mathrm{~min}, 85 \%$ ethanol for $5 \mathrm{~min}$, 
$95 \%$ ethanol for $5 \mathrm{~min}$ and absolute ethanol for $5 \mathrm{~min}$. Then the slices were immersed in xylene for $10 \mathrm{~min}$ and a replaced xylene for $10 \mathrm{~min}$, followed by the addition of neutral gum to the sample with the slide covered after drying. In the final step, the slices were observed under optical microscope for photography of ERK, and Image J software was used for image analysis.

\section{Statistical Analysis}

SPSS 22.0 statistical software was used for data analysis in this experiment. Measurement data were expressed as Mean \pm Standard Deviation (SD). One-way analysis of variance was used for the comparison between groups, and LSD method for pairwise comparison. $P<0.05$ indicated that the difference was statistically significant.

\section{Results}

Clinical data and analysis

By HE staining, Figure 1A shown that the infiltration and invasion of cancer tissues were higher than that of adjacent normal tissues. By IHC assay, Figure 1B shown that CD59 protein expression of Cancer tissues were significantly up-regulation compared with that of adjacent tissues $(\mathrm{P}<0.001)$; Figure $1 \mathrm{C}$ shown that Erk protein expression of Cancer tissues were significantly up-regulation compared with that of adjacent tissues $(\mathrm{P}<0.0001)$.

ERK had effects in cell proliferation

By MTT assay, Figure 2A shown that the cell viability of ERK + siCD59 and ERK inhibitor groups were significantly depressed compared with that of NC group in MDAMB-231 and MCF-7 cell lines ( $<0.01$, respectively); with ERK inhibitor and CD59 transfection, compared with ERK inhibitor group, the cell viabilities of ERK inhibitor+CD59 groups were significantly up-regulation in MDA-MB-231 and MCF-7 cell lines $(\mathrm{P}<0.01$, respectively). By clone assay, Figure $2 \mathrm{~B} \& 2 \mathrm{C}$ shown that clone cell number of ERK+siCD59 and ERK inhibitor groups were significantly depressed 
compared with that of NC group in MDA-MB-231 and MCF-7 cell lines $(\mathrm{P}<0.01$, respectively); with ERK inhibitor and CD59 transfection, compared with ERK inhibitor group, the clone cell number of ERK inhibitor+CD59 groups were significantly upregulation in MDA-MB-231 and MCF-7 cell lines ( $\mathrm{P}<0.01$, respectively).

ERK had effects to cell apoptosis by cell TUNEL assay

By cell TUNEL assay, Figure 3A \& 3B shown Apoptosis cell number of ERK + siCD59 and ERK inhibitor groups were significantly increased compared with that of NC groups in MDA-MB-231 and MCF-7 cell lines ( $\mathrm{P}<0.01$, respectively); with ERK inhibitor and CD59 transfection, compared with ERK inhibitor group, the apoptosis cell number of ERK inhibitor+CD59 groups were significantly downregulation in MDA-MB-231 and MCF-7 cell lines ( $\mathrm{P}<0.01$, respectively).

ERK had effect to cell apoptosis by flow cytometry

By flow cytometry, Figure 4A\&4B shown apoptosis rate of ERK+siCD59 and ERK inhibitor groups were significantly increased compared with that of NC groups in MDA-MB-231 and MCF-7 cell lines ( $<0.01$, respectively); with ERK inhibitor and CD59 transfection, compared with ERK inhibitor group, the apoptosis rate of ERK inhibitor+CD59 groups were significantly down-regulation in MDA-MB-231 and MCF-7 cell lines $(\mathrm{P}<0.01$, respectively).

ERK had effect to cell cycle by flow cytometry

By flow cytometry, Figure 5A\&5B shown G1 phase rate of ERK+siCD59 and ERK inhibitor groups were significantly increased compared with that of NC groups in MDA-MB-231 and MCF-7 cell lines ( $\mathrm{P}<0.01$, respectively); with ERK inhibitor and CD59 transfection, compared with ERK inhibitor group, the G1 phase rate of ERK inhibitor+CD59 groups were significantly down-regulation in MDA-MB-231 and MCF-7 cell lines $(\mathrm{P}<0.01$, respectively); However, G2 phase rate of ERK + siCD59 and ERK inhibitor groups were significantly depressed compared with that of NC groups 
in MDA-MB-231 and MCF-7 cell lines ( $\mathrm{P}<0.01$, respectively); with ERK inhibitor and CD59 transfection, compared with ERK inhibitor group, the G2 phase rate of ERK inhibitor+CD59 groups were significantly up-regulation in MDA-MB-231 and MCF-7 cell lines $(\mathrm{P}<0.01$, respectively).

ERK had effect to cell invasion abilities by transwell assay

By trnaswell assay, Figure 6A \& 6B shown invasion cell number of ERK+siCD59 and ERK inhibitor groups were significantly depressed compared with that of NC groups in MDA-MB-231 and MCF-7 cell lines $(\mathrm{P}<0.01$, respectively); with ERK inhibitor and CD59 transfection, compared with ERK inhibitor group, the G1 phase rate of ERK inhibitor+CD59 groups were significantly increased in MDA-MB-231 and MCF-7 cell lines $(\mathrm{P}<0.01$, respectively).

ERK had effect to cell migration abilities by wound healing assay

By wound healing assay, Figure 7A \& 7B shown wound healing rate of ERK+siCD59 and ERK inhibitor groups were significantly depressed compared with that of NC groups in MDA-MB-231 and MCF-7 cell lines at $24 \mathrm{~h}$ and $48 \mathrm{~h}(\mathrm{P}<0.01$, respectively); with ERK inhibitor and CD59 transfection, compared with ERK inhibitor group, the wound healing rate of ERK inhibitor+CD59 groups were significantly increased in MDA-MB-231 and MCF-7 cell lines at $24 \mathrm{~h}$ and $48 \mathrm{~h}(\mathrm{P}<0.01$, respectively).

ERK had effect to cell adhesion abilities

By cell adhesion assay, Figure 8A \& 8B shown adhesion cell number of ERK + siCD59 and ERK inhibitor groups were significantly depressed compared with that of NC groups in MDA-MB-231 and MCF-7 cell lines $(\mathrm{P}<0.01$, respectively); with ERK inhibitor and CD59 transfection, compared with ERK inhibitor group, adhesion cell number of ERK inhibitor+CD59 groups were significantly increased in MDA-MB231 and MCF-7 cell lines ( $\mathrm{P}<0.01$, respectively). 
The relative protein expression by WB assay

By WB assay, Figure 9A \& 9B shown CD59, PKD and E-cadherin proteins expressions of ERK + siCD59 and ERK inhibitor groups were significantly depressed and P53 and Vimentin proteins expression of ERK+siCD59 and ERK inhibitor groups were significantly increased compared with those of NC groups in MDA-MB-231 and MCF-7 cell lines $(\mathrm{P}<0.01$, respectively); With ERK inhibitor and CD59 transfection, CD59, PKD and E-cadherin proteins expressions of ERK inhibitor+CD59 groups were significantly depressed and P53 and Vimentin proteins expression of ERK inhibitor+CD59 groups were significantly increased compared with those of ERK inhibitor groups in MDA-MB-231 and MCF-7 cell lines ( $\mathrm{P}<0.01$, respectively).

ERK had effects to cell proliferation and apoptosis in vivo

By tumor-bearing experiment, Figure 10A shown that tumor weight and volume of ERK+siCD59 and ERK inhibitor groups were significantly depressed compared with that of $\mathrm{NC}$ groups $(\mathrm{P}<0.01$, respectively); with ERK inhibitor and CD59 transfection, compared with ERK inhibitor group, tumor weight and volume of ERK inhibitor+CD59 groups were significantly increased $(\mathrm{P}<0.01$, respectively). By HE staining, with siCD59 or ERK inhibitor transfection, Figure 10B shown the tissues invasion and infiltration were suppressed, however, with CD59 supplement, the tissues invasion and infiltration were recovery. In order to evaluate cell apoptosis, measuring apoptosis cell number by TUNEL assay, compared with NC group, the apoptosis cell number of ERK + siCD59 and ERK inhibitor groups were significantly up-regulation $(\mathrm{P}<0.01$, respectively); with ERK inhibitor and CD59 transfection, the apoptosis cell number of ERK inhibitor+CD59 group was significantly depressed compared with that of ERK inhibitor group $(\mathrm{P}<0.001)$.

The relative protein expressions in difference tissues by IHC assay

By IHC assay, Figure 11 shown CD59, PKD and E-cadherin proteins expressions of ERK+siCD59 and ERK inhibitor groups were significantly depressed and P53 and Vimentin proteins expression of ERK + siCD59 and ERK inhibitor groups were 
significantly increased compared with those of $\mathrm{NC}$ group $(\mathrm{P}<0.01$, respectively); With ERK inhibitor and CD59 transfection, CD59, PKD and E-cadherin proteins expressions of ERK inhibitor+CD59 groups were significantly depressed and P53 and Vimentin proteins expression of ERK inhibitor+CD59 group were significantly increased compared with those of ERK inhibitor group ( $\mathrm{P}<0.01$, respectively).

\section{Discussion}

In this study, it was found that there was significant increase in the protein expression of ERK and CD59 in breast cancer tissues by detecting clinical specimens. It is thus speculated that ERK may affect the occurrence and development of breast cancer through regulating CD59 expression. Besides, based on the results of in vitro cell and in vivo tumor-bearing experiments, the biological activities (proliferation, invasion and migration) of breast tumor cells were obviously inhibited and the expression of CD59 protein was significantly decreased after silencing ERK. However, simultaneous transfection of CD59 into cells resulted in the disappeared inhibitory effect of ERK inhibitor on breast tumor cells, suggesting that CD59 might be regulated by ERK signaling pathway. Further detection focused on signaling pathway related proteins for the exploration of the related mechanism. The results showed that ERK/CD59 signaling pathway associated intimately with protein kinase D (PKD), P53, E-cadherin and Vimentin.

PKD can promote the activation of tumor associated protein kinase in tumor cells, enhance the activity of upstream transcription genes, as well as accelerate the proliferation, and enhance the proliferation and migration of tumor cells [12-14]. PKD can improve invasion and self-renewal of tumor cells by promoting the change of biological characteristics of tumor cells [15-17]. Previous studies have reported that PKD can negatively regulate P53 expression $[18,19]$. P53 is one of the known tumor suppressor genes found to be highly correlated with great majority of human cancers [20]. The normal P53 protein expression product has a short half-life and is not detectable, which is able to inhibit tumor cell proliferation and induce apoptosis. However, mutation of P53 may result in the prolonged half-life of expression product 
that can be detected. The mutated P53 not only loses the function of tumor suppression, but also can induce normal cells to transform into tumor cells. Simultaneously, it can block the tumor suppression effect of wild-type P53 without mutation, and finally promote the occurrence and progression of tumors [21, 22]. In our study, with ERK gene expression silenced, there was decreased expression of CD59, obvious inhibited expression of PKD, while evident increased expression of P53, which further led to a large number of cells stagnated in G1 phase, leading to a significant increase of apoptosis rate $[23,24]$. It may primarily explains that inhibiting the activation of ERK/CD59 pathway may eventually induce an evident decrease in cell proliferation and a significant increase in cell apoptosis.

The epithelial-mesenchymal transition (EMT) is an important step in further development and metastasis of cancer. EMT starts with the diminished cell polarity and cell-cell adhesion in cancer cells, leading to enhanced migratory and invasive properties. In breast cancer, EMT can occur through multiple extracellular signaling pathways [2527]. E-cadherin and Vimentin are two critical proteins that play an important role in the development of EMT [28, 29]. To be specific, the decrease of E-cadherin and the increase of Vimentin are related to the migration, invasion and adhesion of tumor cells, which are the key factors leading to poor prognosis of cancer patients [30, 31]. In this study, the invasion, migration and adhesion of breast cancer cells were significantly inhibited after blocking ERK/CD59 signaling pathway, which may be related to the changes of E-cadherin and vimentin.

In conclusion, ERK can positively regulate CD59, promote cell proliferation, inhibit apoptosis and induce EMT in the course of breast cancer. Furthermore, inhibition of the activation of ERK/CD59 pathway results in decreased PKD expression, but increased PTEN tumor suppressor gene expression, which promotes cell apoptosis and inhibits cell proliferation. Besides, it effectively inhibits the EMT process of breast cancer cells.

\section{Ethics Approval}

In view of the approval and validity of the animal experiments approved by the 
Ethics Committee of the People's Hospital of Jiangxi Province, the Ethics Committee of the Laboratory Animal Center of Jiangxi University of Traditional Chinese Medicine also agreed to the animal experiment.

\section{Author Contributions}

All authors contributed to data analysis, drafting or revising the article, gave final approval of the version to be published, and have agreed to be accountable for all aspects of the work.

\section{Funding}

This study was supported by National Natural Science Foundation of China (Grant/Award Number: 81760527) and Jiangxi University of Traditional Chinese Medicine, Grant/Award Numbers (JXSYLXK-ZHYAO123\& JXSYLXK-ZHYAO134)

\section{Disclosure}

The authors report no conflicts of interest in this work.

\section{References:}

[1] Burnett RM, Craven KE, Krishnamurthy P, et al. Organ-specific adaptive signaling pathway activation in metastatic breast cancer cells. Oncotarget 6(2015); 12682-96.

[2] Siegel R, Ma J, Zou Z, et al. Cancer statistics, 2014. CA Cancer J Clin 64(2014);929.

[3] Lim E, Lin NU. Updates on the management of breast cancer brain metastases. Oncology (Williston Park) 28(2014);572-8.

[4] Cho MS, Vasquez HG, Rupaimoole R, et al. Autocrine effects of tumor-derived complement. Cell Rep 6(2014);1085-1095.

[5] Fishelson Z, Donin N, Zell S, et al. Obstacles to cancer immunotherapy: expression of membrane complement regulatory proteins (mCRPs) in tumors. Mol Immunol 40(2003); 109-23.

[6] Goswami MT, Reka AK, Kurapati H, et al. Regulation of complement-dependent 
cytotoxicity by TGF- $\beta$-induced epithelial-mesenchymal transition. Oncogene 35(2016);1888-98.

[7] Mamidi S, Cinci M, Hasmann M, et al. Lipoplex mediated silencing of membrane regulators (CD46, CD55 and CD59) enhances complement-dependent anti-tumor activity of trastuzumab and pertuzumab. Mol Oncol 7(2013);580-94.

[8] Terp MG, Lund RR, Jensen ON, et al. Identification of markers associated with highly aggressive metastatic phenotypes using quantitative comparative proteomics. Cancer Genomics Proteomics 9(2012); 265-73.

[9] Liu M, Yang YJ, Zheng H, et al. Membrane-bound complement regulatory proteins are prognostic factors of operable breast cancer treated with adjuvant trastuzumab. Oncol Rep 32(2014); 2619-27.

[10] Simões AE, Rodrigues CM, Borralho PM. The MEK5/ERK5 signalling pathway in cancer: a promising novel therapeutic target. Drug Discov Today 21(2016);1654-1663.

[11] Qianwen Ouyang, Long Zhang, Yizhou Jiang, et al. The membrane complement regulatory protein CD59 promotes tumor growth and predicts poor prognosis in breast cancer. Int J Oncol. 2016 May;48(5):2015-24.

[12] Wang Y, Hoeppner LH, Angom RS, et al. Protein kinase D up-regulates transcription of VEGF receptor-2 in endothelial cells by suppressing nuclear localization of the transcription factor AP2ß. J Biol Chem 294(2019);15759-15767.

[13] Zhang Y, Wang HH, Wan X, et al. Inhibition of protein kinase D disrupts spindle formation and actin assembly during porcine oocyte maturation. Aging (Albany NY) 10(2018); 3736-3744.

[14] Li QQ, Hsu I, Sanford T, et al. Protein kinase D inhibitor CRT0066101 suppresses bladder cancer growth in vitro and xenografts via blockade of the cell cycle at G2/M. Cell Mol Life Sci 75(2018); 939-963.

[15] Maier D, Nagel AC, Kelp A, et al. Protein Kinase D Is Dispensable for Development and Survival of Drosophila melanogaster. G3 (Bethesda) 9(2019); $2477-2487$.

[16] Qin XJ, Gao ZG, Huan JL, et al. Protein kinase D1 inhibits breast cancer cell 
invasion via regulating matrix metalloproteinase expression. Eur $J$ Gynaecol Oncol 36(2015); 690-3.

[17] Bonfim-Melo A, Zanetti BF, Ferreira ÉR, et al. Trypanosoma cruzi extracellular amastigotes trigger the protein kinase D1-cortactin-actin pathway during cell invasion. Cell Microbiol 17(2015);'1797-810.

[18] Bernhart E, Damm S, Heffeter P, et al. Silencing of protein kinase D2 induces glioma cell senescence via p53-dependent and -independent pathways. Neuro Oncol 16(2014); 933-45.

[19] Ryvkin V, Rashel M, Gaddapara T, et al. Opposing growth regulatory roles of protein kinase D isoforms in human keratinocytes. J Biol Chem 290(2015);11199208.

[20] Luo Y, Fu X, Ru R, et al. CpG Oligodeoxynucleotides Induces Apoptosis of Human Bladder Cancer Cells via Caspase-3-Bax/Bcl-2-p53 Axis. Arch Med Res 51(2020); $233-244$

[21] Alijani Ardeshir R, Rastgar S, Morakabati P, et al. Selective induced apoptosis and cell cycle arrest in MCF7 and LNCap cell lines by skin mucus from round goby (Neogobius melanostomus) and common carp (Cyprinus carpio) through P53 expression. Cytotechnology 72(2020); 367-376.

[23] Zhu X, Luo C, Lin K, et al. Overexpression of DJ-1 enhances colorectal cancer cell proliferation through the cyclin-D1/MDM2-p53 signaling pathway. Biosci Trends 14(2020); 83-95.

[24] Yang B, Bai H, Sa Y, et al. Inhibiting EMT, stemness and cell cycle involved in baicalin-induced growth inhibition and apoptosis in colorectal cancer cells. $J$ Cancer. 11(2020); 2303-2317.

[23] Moreno-Celis U, López-Martínez FJ, Cervantes-Jiménez R, et al. Tepary Bean (Phaseolus acutifolius) Lectins Induce Apoptosis and Cell Arrest in G0/G1 by P53(Ser46) Phosphorylation in Colon Cancer Cells. Molecules. 25(2020);1021.

[25] Cheng CS, Chen JX, Tang J, et al. Paeonol Inhibits Pancreatic Cancer Cell Migration and Invasion Through the Inhibition of TGF- $\beta 1 /$ Smad Signaling and Epithelial-Mesenchymal-Transition. Cancer Manag Res. 12(2020); 641-651. 
[26] Xu Y, Yan YC, Hu YK, et al. WWOX regulates the Elf5/Snaill pathway to affect epithelial-mesenchymal transition of ovarian carcinoma cells in vitro. Eur Rev Med Pharmacol Sci. 24(2020); 1041-1053.

[27] Arisan ED, Akar RO, Rencuzogullari O, et al. The molecular targets of diclofenac differs from ibuprofen to induce apoptosis and epithelial mesenchymal transition due to alternation on oxidative stress management p53 independently in PC3 prostate cancer cells. Prostate Int. 7(2019); 156-165.

[28] Wang X, Chen S, Shen T, et al. Trichostatin A reverses epithelial-mesenchymal transition and attenuates invasion and migration in MCF-7 breast cancer cells. Exp Ther Med. 19(2020); 1687-1694.

[29] Verma S, Kang AK, Pal R, BST2 regulates interferon gamma-dependent decrease in invasion of HTR-8/SVneo cells via STAT1 and AKT signaling pathways and expression of E-cadherin. Cell Adh Migr. 14(2020);24-41.

[30] Kim H, Shin S, Kim Y, et al. The clinicopathologic significance of extranodal tumor extension in locally advanced (pT3) colorectal adenocarcinoma and its association with the loss of E-cadherin expression. Int J Clin Exp Pathol. 12(2019); $3417-3425$.

[31] Xu X, Zhu H, Yang M, et al. Knockdown of TOR signaling pathway regulator suppresses cell migration and invasion in non-small cell lung cancer via the regulation of epithelial-to-mesenchymal transition. Exp Ther Med. 19(2020); 1925-1932.

Figure legends

Figure 1. Clinical data

A. Pathology of difference tissues by HE staining $(200 \times)$.

B. CD59 protein expression in difference tissues by IHC assay $(400 \times)$ ***: $\mathrm{P}<0.001$, compared with adjacent tissues

C. Erk protein expression in difference tissues by IHC assay $(400 \times)$ 
***: $\mathrm{P}<0.001$, compared with adjacent tissues

Figure 2. ERK had effects in cell proliferation

NC: treated with normal; Mock: transfected with empty vector; ERK: transfected with ERK; ERK+siCD59: transfected with ERK and siCD59 which inhibitor CD59; ERK+CD59: transfected with ERK and CD59; ERK inhibitor: transfected with ERK inhibitor; ERK inhibitor+CD59: transfected with ERK inhibitor and CD59

A. The cell viability of difference groups by MTT assay

B. The Clone cell number of difference MDA-MB-231 cell groups

**: $\mathrm{P}<0.01, * * *: \mathrm{P}<0.001$, compared with $\mathrm{NC}$ group; \#\#: $\mathrm{P}<0.01$, compared with ERK inhibitor group

C. The Clone cell number of difference MCF-7 cell groups

**: $\mathrm{P}<0.01, * * *: \mathrm{P}<0.001$, compared with $\mathrm{NC}$ group; \#\#: $\mathrm{P}<0.01$, compared with ERK inhibitor group

Figure 3. ERK had effects to cell apoptosis by cell TUNEL assay

NC: treated with normal; Mock: transfected with empty vector; ERK: transfected with ERK; ERK+siCD59: transfected with ERK and siCD59 which inhibitor CD59; ERK+CD59: transfected with ERK and CD59; ERK inhibitor: transfected with ERK inhibitor; ERK inhibitor+CD59: transfected with ERK inhibitor and CD59

A. The apoptosis cell number in MDA-MB-231 cell groups by cell TUNEL assay **: $\mathrm{P}<0.01, * * *: \mathrm{P}<0.001$, compared with $\mathrm{NC}$ group; \#\#: $\mathrm{P}<0.01$, compared with ERK inhibitor group

B. The apoptosis cell number in MCF-7 cell groups by cell TUNEL assay **: $\mathrm{P}<0.01, * * *: \mathrm{P}<0.001$, compared with NC group; \#\#: $\mathrm{P}<0.01$, compared with ERK inhibitor group

Figure 4. ERK had effect to cell apoptosis by flow cytometry 
NC: treated with normal; Mock: transfected with empty vector; ERK: transfected with ERK; ERK+siCD59: transfected with ERK and siCD59 which inhibitor CD59; ERK+CD59: transfected with ERK and CD59; ERK inhibitor: transfected with ERK inhibitor; ERK inhibitor+CD59: transfected with ERK inhibitor and CD59

A. The apoptosis rate of difference MDA-MB-231 cell groups **: $\mathrm{P}<0.01, * * *: \mathrm{P}<0.001$, compared with NC group; \#\#: $\mathrm{P}<0.01$, compared with ERK inhibitor group

B. The apoptosis rate of difference MCF-7 cell groups $* *: \mathrm{P}<0.01, * * *: \mathrm{P}<0.001$, compared with $\mathrm{NC}$ group; \#\#: $\mathrm{P}<0.01$, compared with ERK inhibitor group

Figure 5. ERK had effect to cell cycle by flow cytometry NC: treated with normal; Mock: transfected with empty vector; ERK: transfected with ERK; ERK+siCD59: transfected with ERK and siCD59 which inhibitor CD59; ERK+CD59: transfected with ERK and CD59; ERK inhibitor: transfected with ERK inhibitor; ERK inhibitor+CD59: transfected with ERK inhibitor and CD59

A. The cell cycle of difference MDA-MB-231 cell groups **: $\mathrm{P}<0.01, * * *: \mathrm{P}<0.001$, compared with NC group; \#\#: $\mathrm{P}<0.01$, compared with ERK inhibitor group

B. The cell cycle of difference MCF-7 cell groups **: $\mathrm{P}<0.01, * * *: \mathrm{P}<0.001$, compared with NC group; \#\#: $\mathrm{P}<0.01$, compared with ERK inhibitor group

Figure 6. ERK had effect to cell invasion abilities by transwell assay NC: treated with normal; Mock: transfected with empty vector; ERK: transfected with ERK; ERK+siCD59: transfected with ERK and siCD59 which inhibitor CD59; ERK+CD59: transfected with ERK and CD59; ERK inhibitor: transfected with ERK inhibitor; ERK inhibitor+CD59: transfected with ERK inhibitor and CD59 
A. MDA-MB-231 invasion cell number of difference groups

**: $\mathrm{P}<0.01, * * *: \mathrm{P}<0.001$, compared with NC group; \#\#: $\mathrm{P}<0.01$, compared with ERK inhibitor group

B. MCF-7 invasion cell number of difference groups

**: $\mathrm{P}<0.01, * * *: \mathrm{P}<0.001$, compared with NC group; \#\#: $\mathrm{P}<0.01$, compared with ERK inhibitor group

Figure 7. ERK had effect to cell migration abilities by wound healing assay

NC: treated with normal; Mock: transfected with empty vector; ERK: transfected with ERK; ERK+siCD59: transfected with ERK and siCD59 which inhibitor CD59; ERK+CD59: transfected with ERK and CD59; ERK inhibitor: transfected with ERK inhibitor; ERK inhibitor+CD59: transfected with ERK inhibitor and CD59

A. Wound healing rate of MDA-MB-231 cell groups

$* *: \mathrm{P}<0.01,{ }^{* * *}: \mathrm{P}<0.001$, compared with $\mathrm{NC}$ group; \#\#: $\mathrm{P}<0.01$, compared with ERK inhibitor group

B. Wound healing rate of $\mathrm{MCF}-7$ cell groups

**: $\mathrm{P}<0.01, * * *: \mathrm{P}<0.001$, compared with NC group; \#\#: $\mathrm{P}<0.01$, compared with ERK inhibitor group

Figure 8. ERK had effect to cell adhesion abilities

NC: treated with normal; Mock: transfected with empty vector; ERK: transfected with ERK; ERK+siCD59: transfected with ERK and siCD59 which inhibitor CD59; ERK+CD59: transfected with ERK and CD59; ERK inhibitor: transfected with ERK inhibitor; ERK inhibitor+CD59: transfected with ERK inhibitor and CD59

A. Adherent MDA-MB-231 cell number $* *: \mathrm{P}<0.01, * * *: \mathrm{P}<0.001$, compared with $\mathrm{NC}$ group; \#\#: $\mathrm{P}<0.01$, compared with ERK inhibitor group 
B. Adherent MCF-7 cell number

**: $\mathrm{P}<0.01,{ }^{* * *}: \mathrm{P}<0.001$, compared with NC group; \#\#: $\mathrm{P}<0.01$, compared with ERK inhibitor group

Figure 9. Relative proteins expression by WB assay

NC: treated with normal; Mock: transfected with empty vector; ERK: transfected with ERK; ERK+siCD59: transfected with ERK and siCD59 which inhibitor CD59; ERK+CD59: transfected with ERK and CD59; ERK inhibitor: transfected with ERK inhibitor; ERK inhibitor+CD59: transfected with ERK inhibitor and CD59

A. Relative proteins expression in MDA-MB-231 cell groups **: $\mathrm{P}<0.01, * * *: \mathrm{P}<0.001$, compared with $\mathrm{NC}$ group; \#\#: $\mathrm{P}<0.01$, compared with ERK inhibitor group

B. Relative proteins expression in MCF-7 cell groups

**: $\mathrm{P}<0.01,{ }^{* * *}: \mathrm{P}<0.001$, compared with NC group; \#\#: $\mathrm{P}<0.01$, compared with ERK inhibitor group

Figure 10. ERK had effects to cell proliferation and apoptosis in vivo NC: treated with normal; Mock: transfected with empty vector; ERK: transfected with ERK; ERK+siCD59: transfected with ERK and siCD59 which inhibitor CD59; ERK+CD59: transfected with ERK and CD59; ERK inhibitor: transfected with ERK inhibitor; ERK inhibitor+CD59: transfected with ERK inhibitor and CD59

A. Tumor weight and volume of difference gours **: $\mathrm{P}<0.01,{ }^{* * *}: \mathrm{P}<0.001$, compared with $\mathrm{NC}$ group; \#\#: $\mathrm{P}<0.01$, compared with ERK inhibitor group

B. The Pathology of tumor tissues in difference groups

C. The apoptosis cell number of difference groups by TUNEL assay in vivo $* *: \mathrm{P}<0.01, * * *: \mathrm{P}<0.001$, compared with $\mathrm{NC}$ group; \#\#: $\mathrm{P}<0.01$, compared with ERK inhibitor group 
Figure 11. The relative protein expression of tumor tissues in difference groups NC: treated with normal; Mock: transfected with empty vector; ERK: transfected with ERK; ERK+siCD59: transfected with ERK and siCD59 which inhibitor CD59; ERK+CD59: transfected with ERK and CD59; ERK inhibitor: transfected with ERK inhibitor; ERK inhibitor+CD59: transfected with ERK inhibitor and CD59

A. CD59 protein expression in difference groups by IHC assay $(400 \times)$ **: $\mathrm{P}<0.01, * * *: \mathrm{P}<0.001$, compared with $\mathrm{NC}$ group; \#\#: $\mathrm{P}<0.01$, compared with ERK inhibitor group

B. PKD protein expression in difference groups by IHC assay $(400 \times)$ **: $\mathrm{P}<0.01, * * *: \mathrm{P}<0.001$, compared with NC group; \#\#: $\mathrm{P}<0.01$, compared with ERK inhibitor group

C. P53 protein expression in difference groups by IHC assay $(400 \times)$ **: $\mathrm{P}<0.01, * * *: \mathrm{P}<0.001$, compared with NC group; \#\#: $\mathrm{P}<0.01$, compared with ERK inhibitor group

D. E-cadherin protein expression in difference groups by IHC assay $(400 \times)$ **: $\mathrm{P}<0.01,{ }^{* * *}: \mathrm{P}<0.001$, compared with NC group; \#\#: $\mathrm{P}<0.01$, compared with ERK inhibitor group

E. Vimentin protein expression in difference groups by IHC assay $(400 \times)$ **: $\mathrm{P}<0.01,{ }^{* * *}: \mathrm{P}<0.001$, compared with NC group; \#\#: $\mathrm{P}<0.01$, compared with ERK inhibitor group 
A
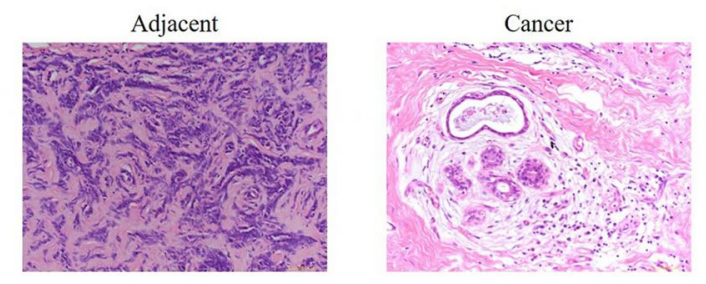

B

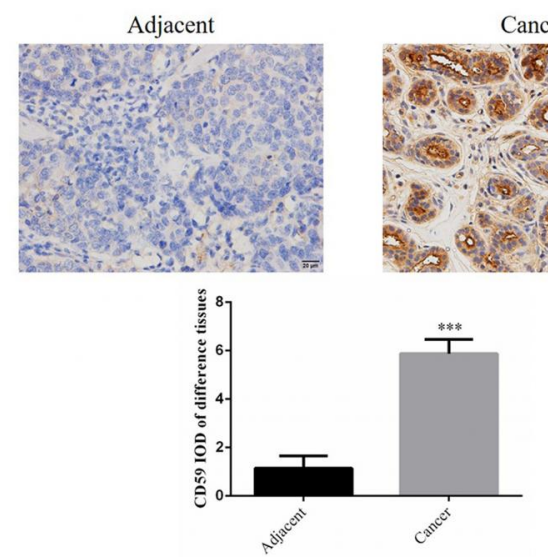

C
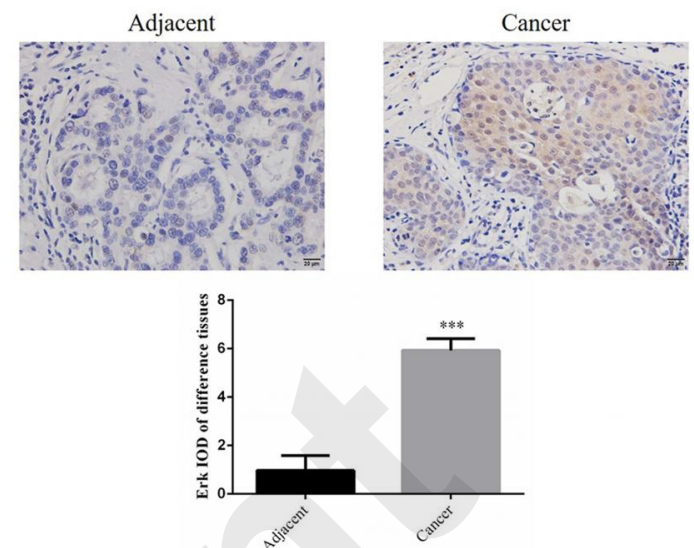

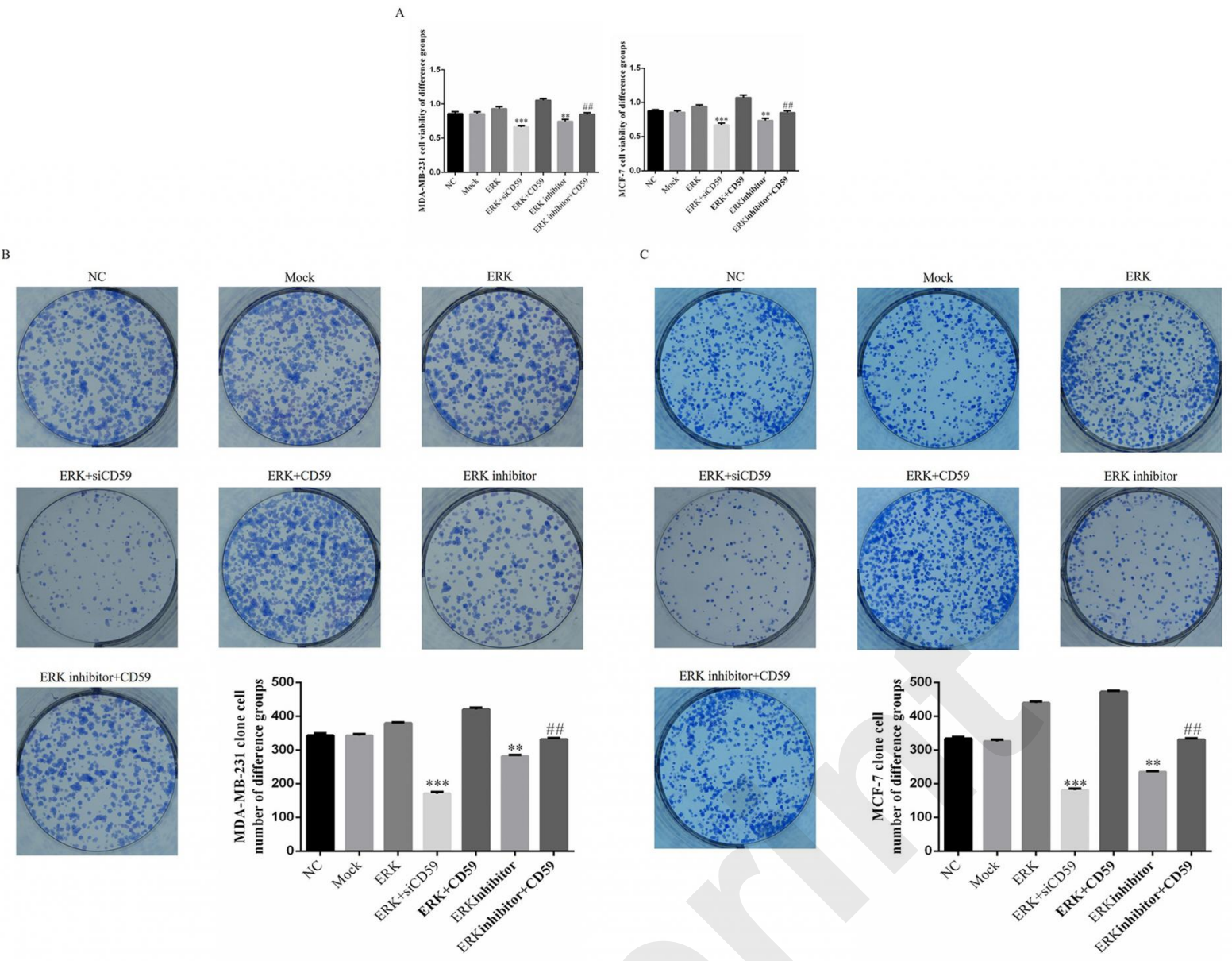


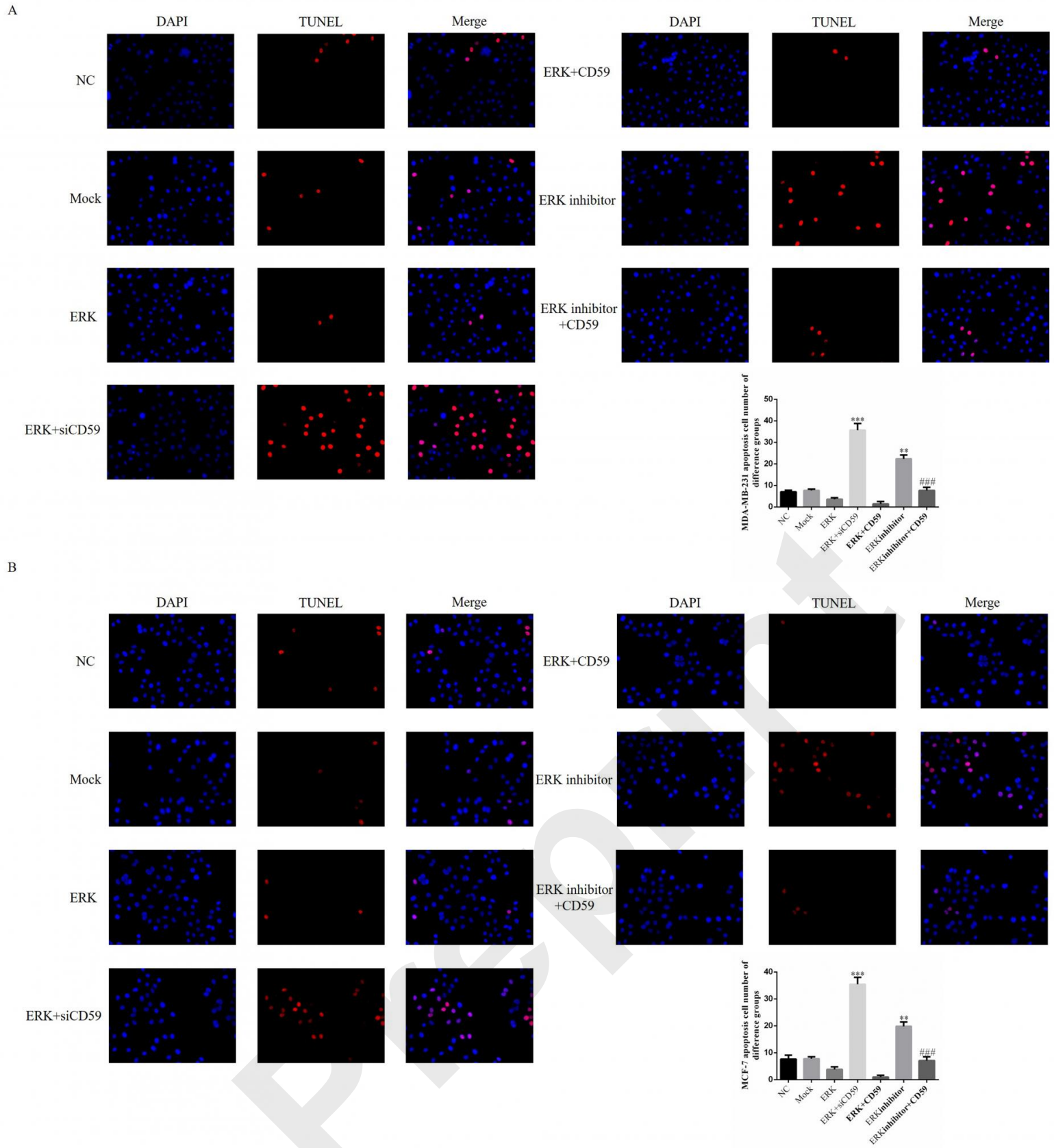




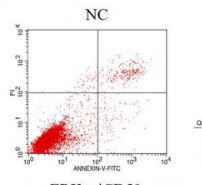

ERK + siCD59

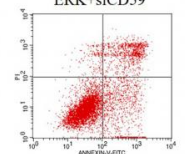

ERK inhibitor + CD59

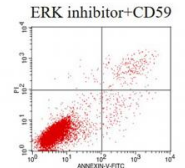

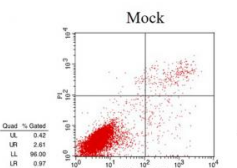

迹

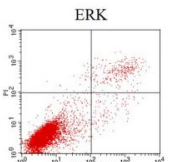

ERK +CD59

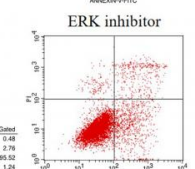

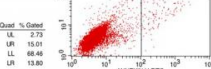

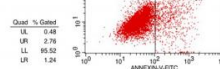

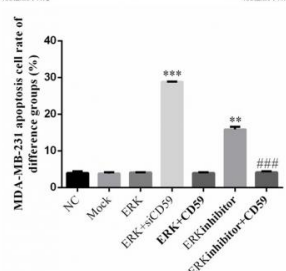

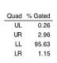

筁

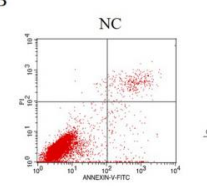

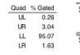
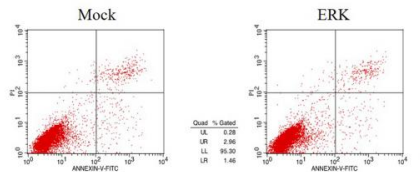

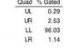

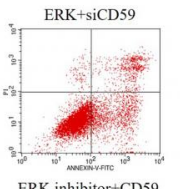

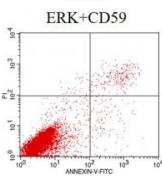

ERK inhibitor

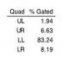

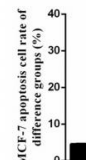

눈

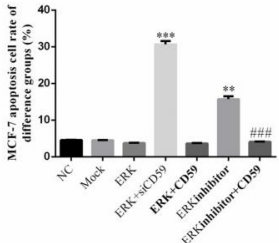



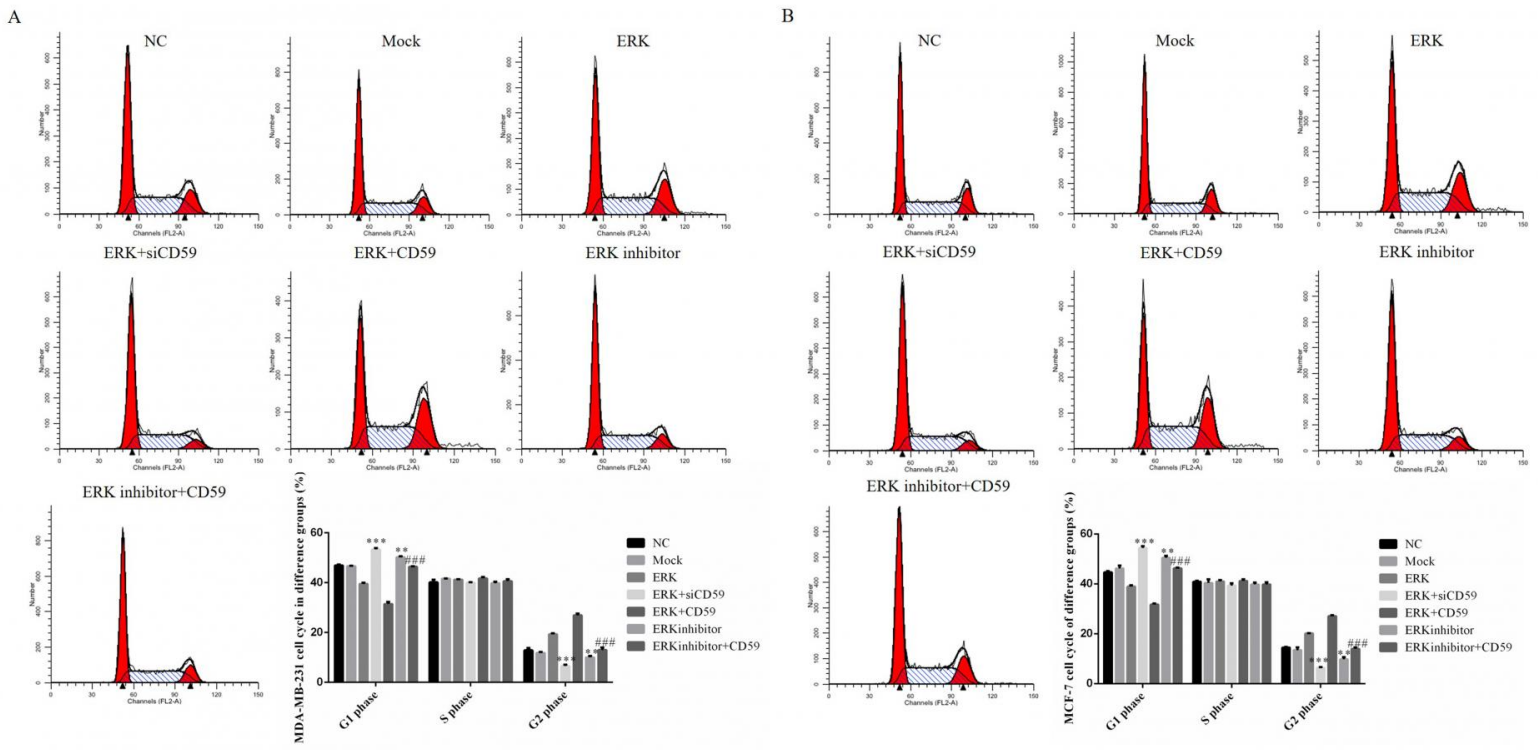
A
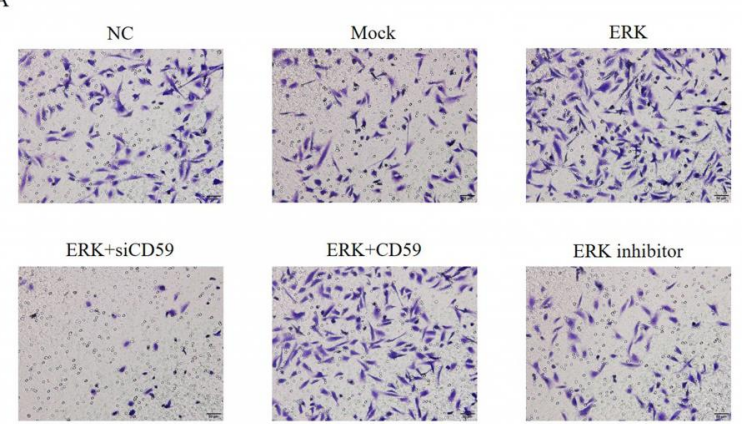

ERK inhibitor+CD59
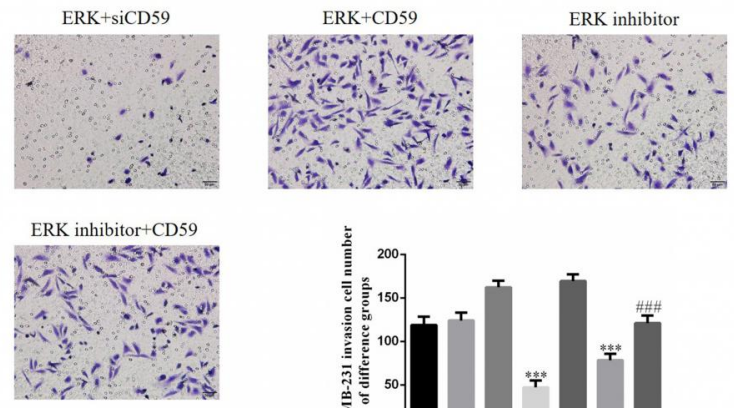

B
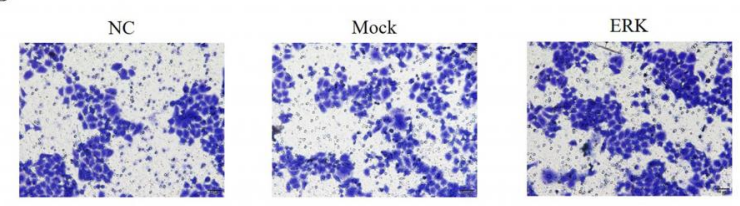

ERK + siCD59
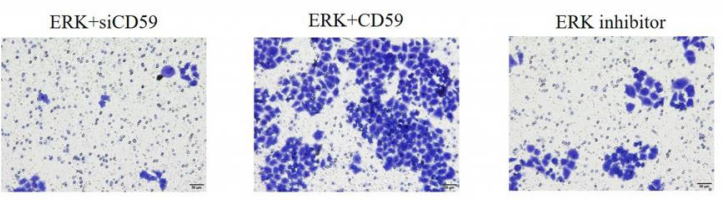

ERK inhibitor + CD59

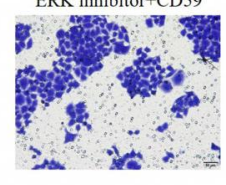

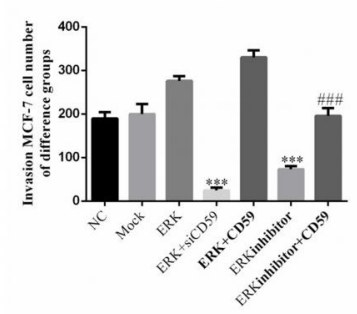

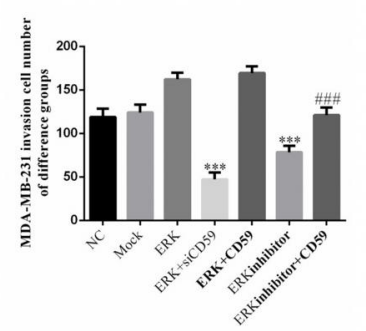




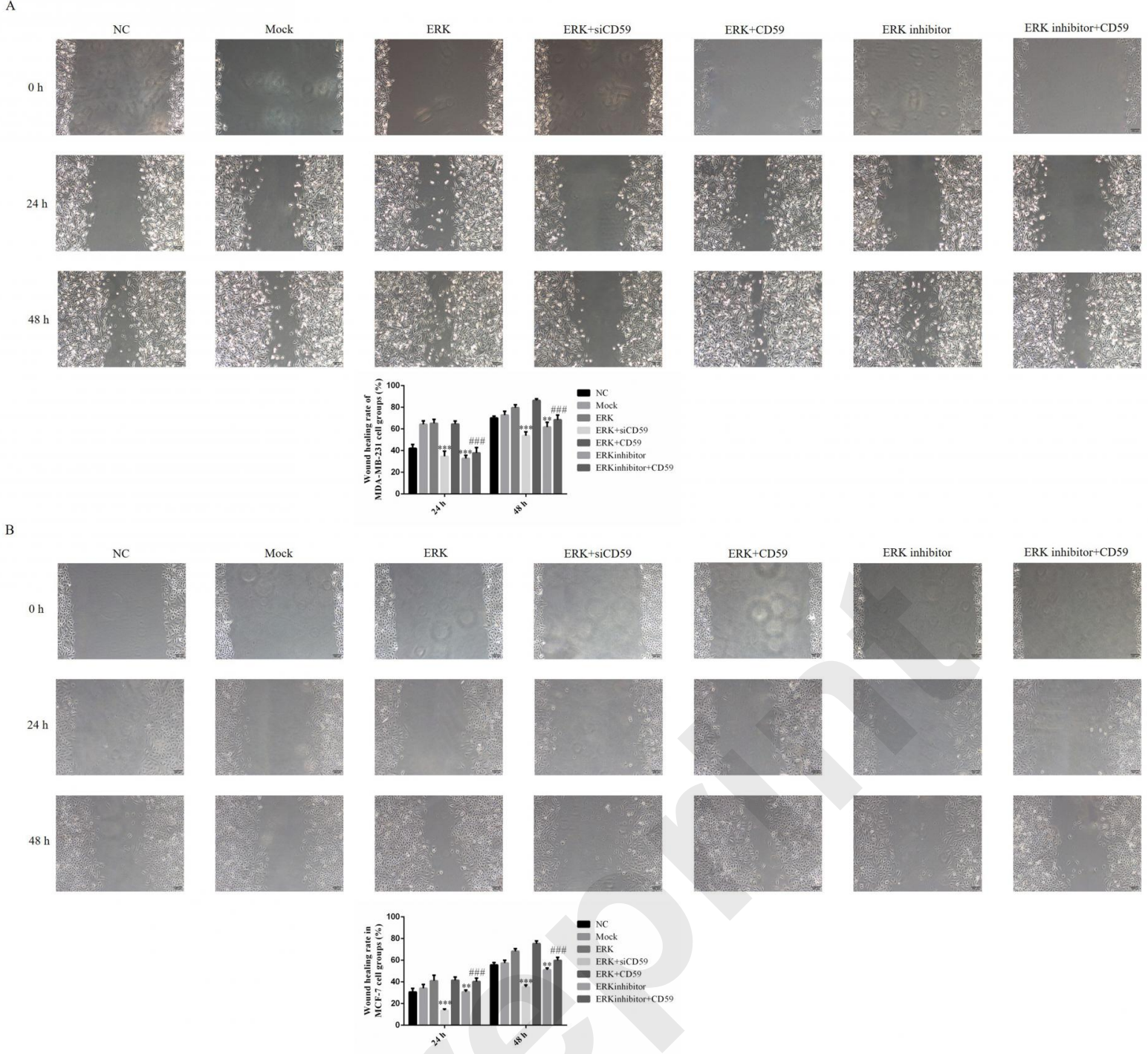




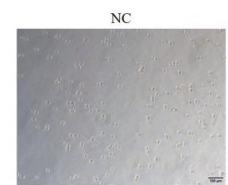

ERK+siCD59

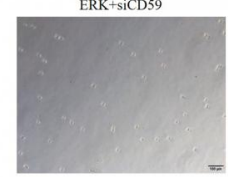

ERK inhibitor - CD59

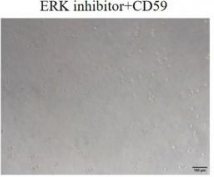

Mock

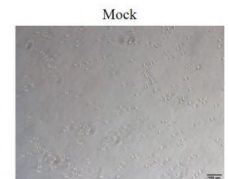

ERK+CD59

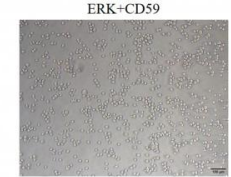

|IIIIII

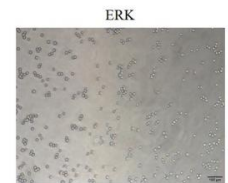

ERK inhibitor
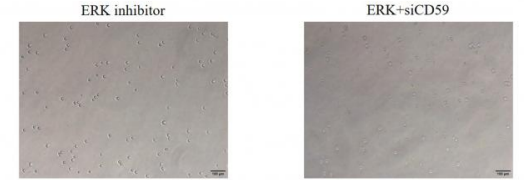

ERK inhibitor + CD59

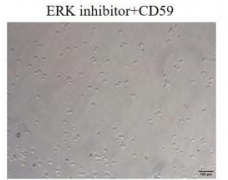

Mock

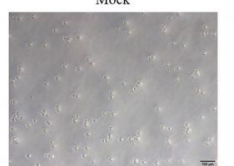

ERK+CD59
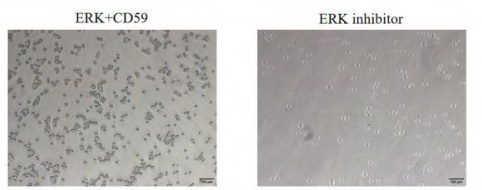

AIIIIII

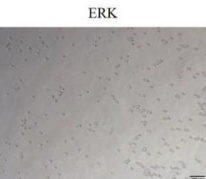

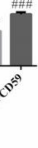


A

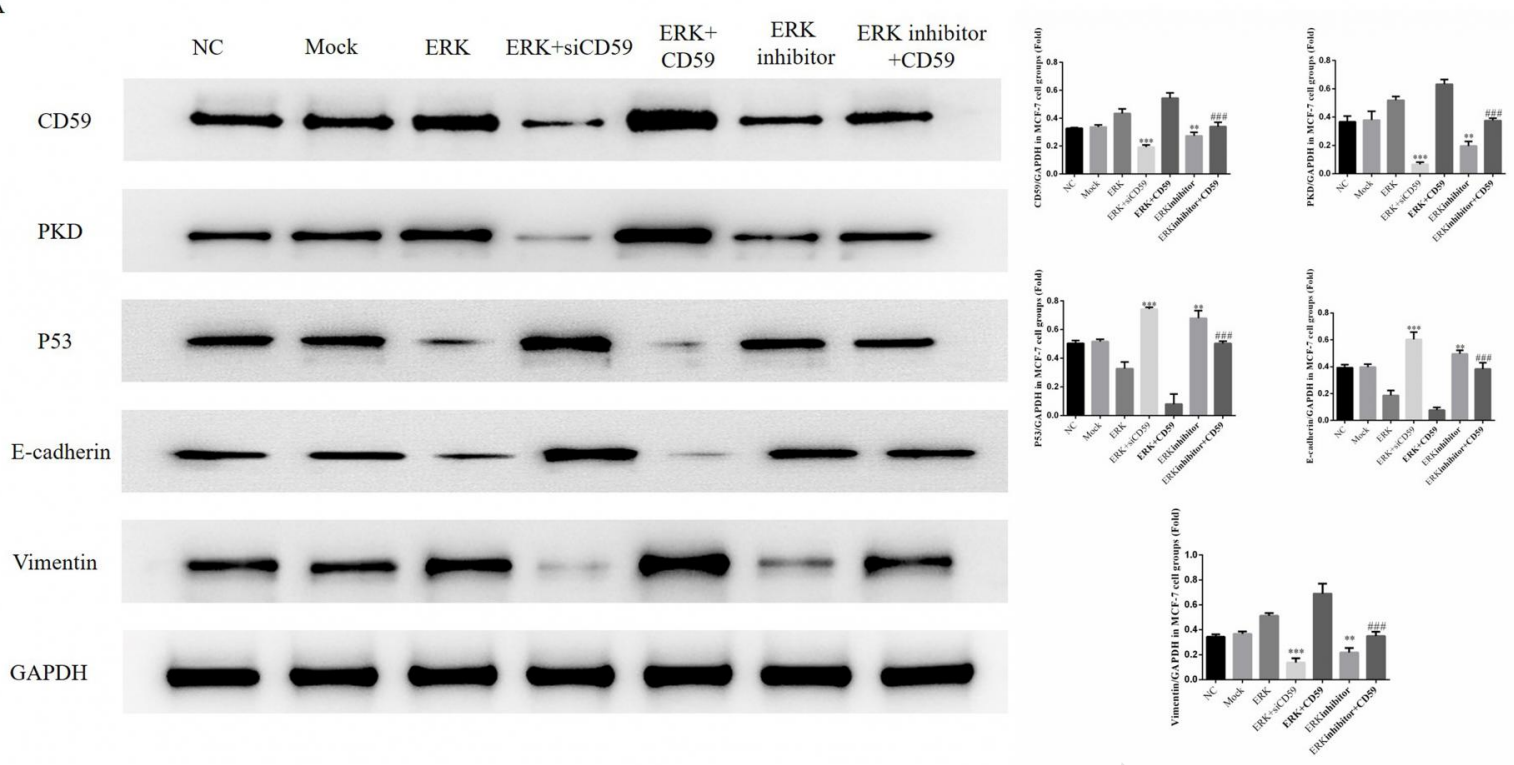

B

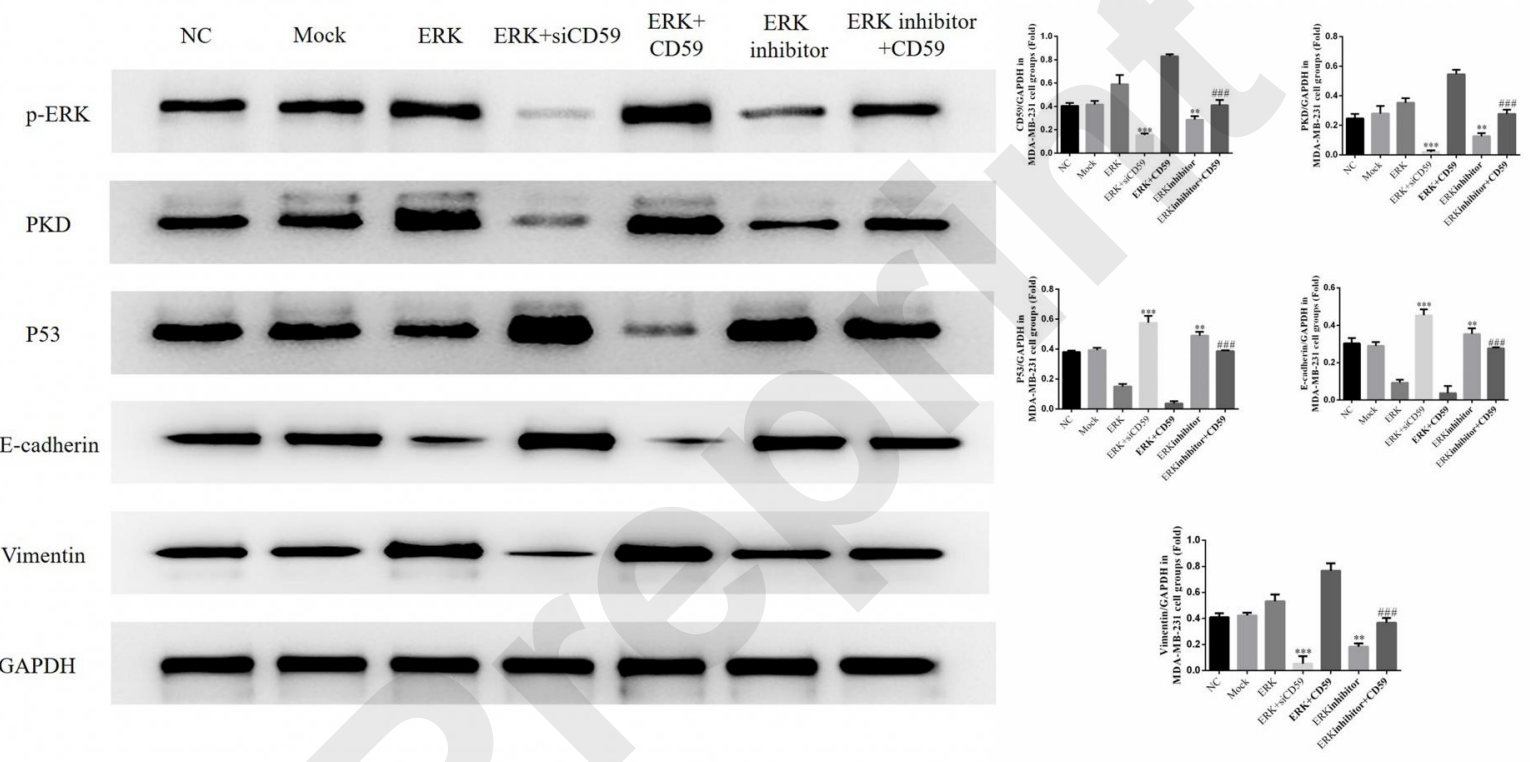



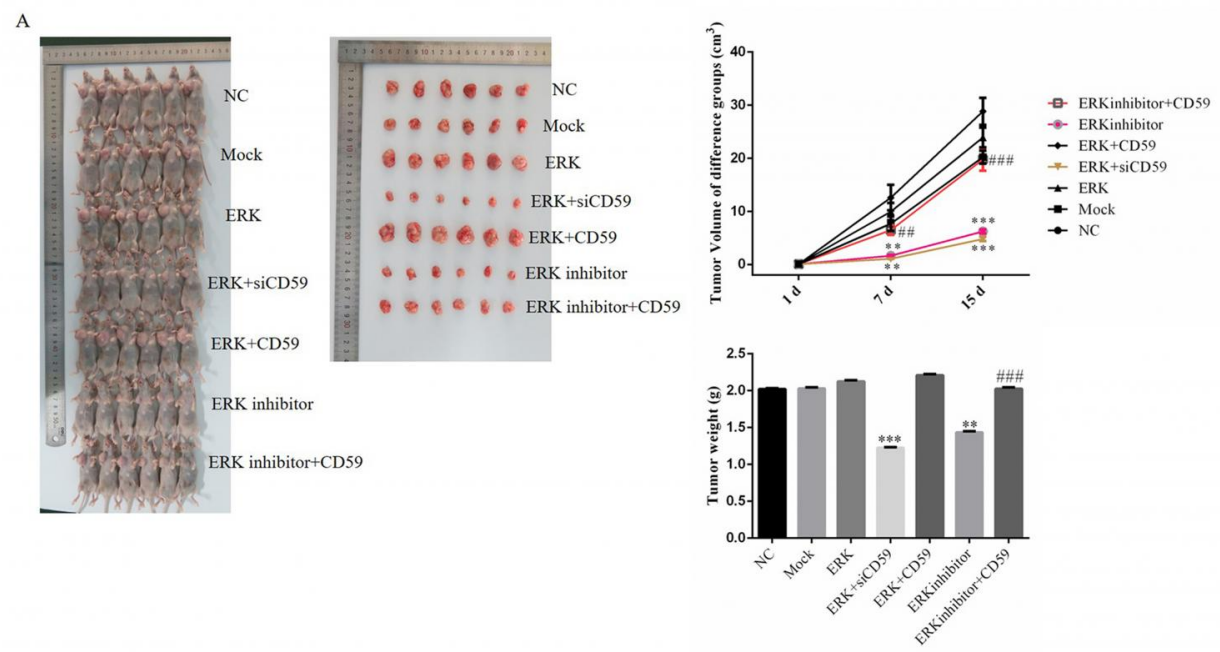

B
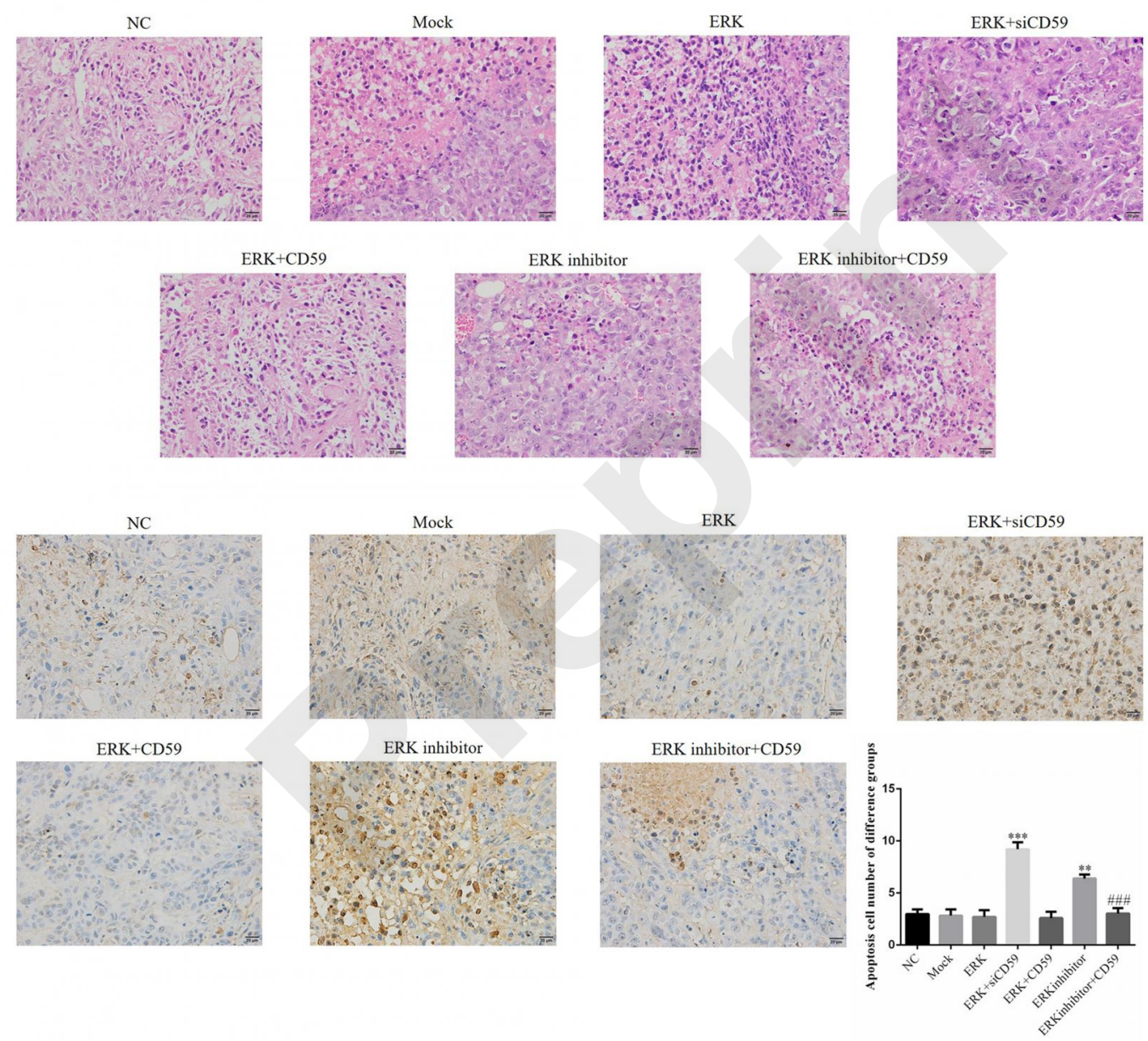

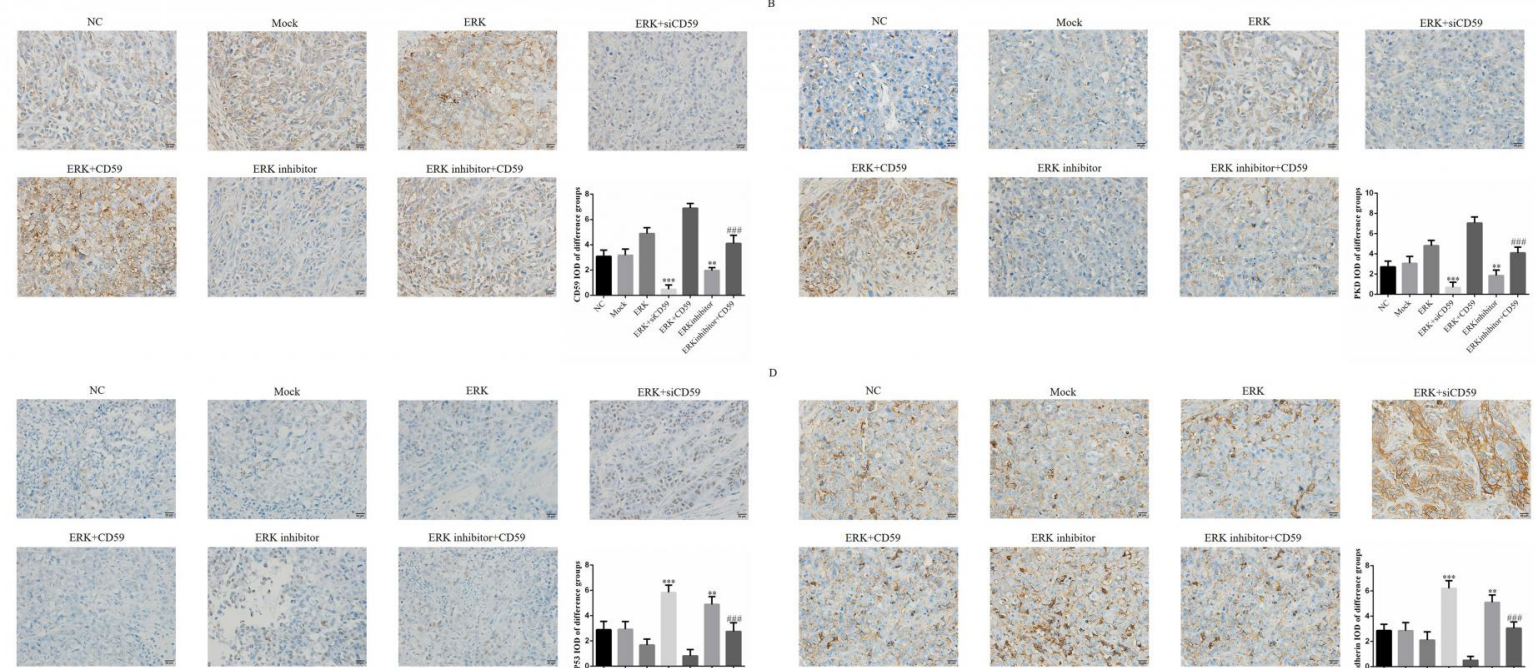

ERK inhbibitr-CD59
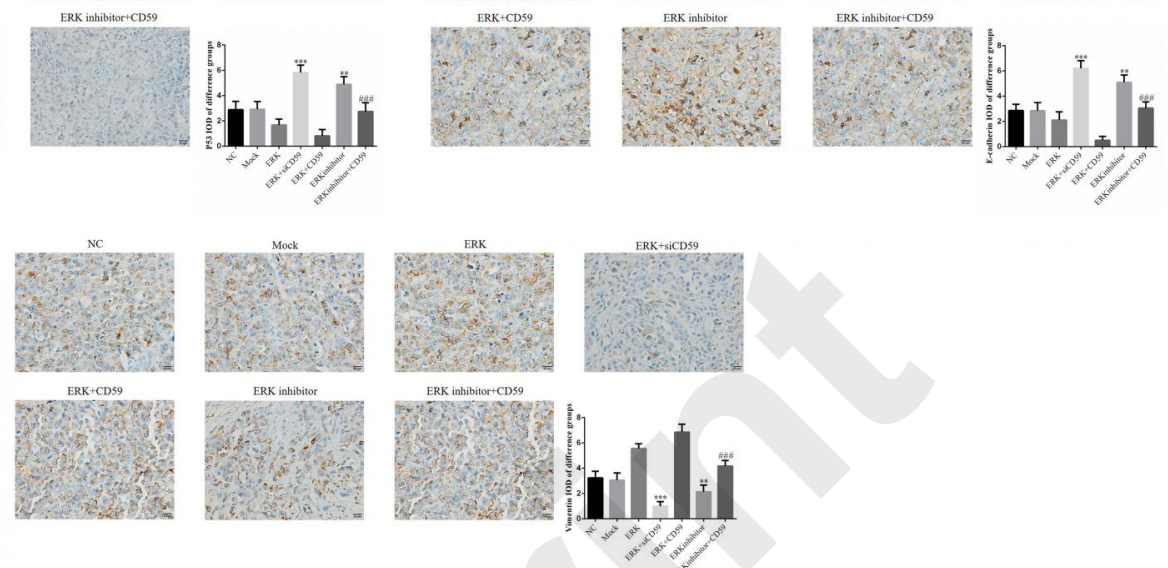